\title{
Effects of Prior Vegetative Growth, Inoculum Density, Light, and Mating on Conidiation of Erysiphe necator
}

\author{
David M. Gadoury, Laura M. Wakefield, Lance Cadle-Davidson, Ian B. Dry, and Robert C. Seem
}

First, second, and fifth authors: Department of Plant Pathology and Plant-Microbe Biology, Cornell University, New York State Agricultural Experiment Station, Geneva 14456; third author: United States Department of Agriculture-Agricultural Research Service Grape Genetics Research Unit, New York State Agricultural Experiment Station; and fourth author: Commonwealth Scientific and Industrial Research Organisation, Plant Industry, Urrbrae, SA 5064, Australia.

Accepted for publication 9 August 2011.

\begin{abstract}
Gadoury, D. M., Wakefield, L. M., Cadle-Davidson, L., Dry, I. B., and Seem, R. C. 2012. Effects of prior vegetative growth, inoculum density, light, and mating on conidiation of Erysiphe necator. Phytopathology 102:65-72.

Initiation of asexual sporulation in powdery mildews is preceded by a period of superficial vegetative growth of mildew colonies. We found evidence of a quorum-sensing signal in Erysiphe necator that was promulgated at the colony center and stimulated conidiation throughout the colony. Removal of the colony center after putative signal promulgation had no impact upon timing of sporulation by 48-h-old hyphae at the colony margin. However, removal of the colony center before signaling nearly doubled the latent period. A relationship between inoculum density and latent period was also observed, with latent period decreasing as the number of conidia deposited per square millimeter was increased.

above 10 spores $/ \mathrm{mm}$. Furthermore, light was shown to be necessary to initiate conidiation of sporulation-competent colonies. When plants were inoculated and maintained in a day-and-night cycle for $36 \mathrm{~h}$ but subjected to darkness after $36 \mathrm{~h}$, colonies kept in darkness failed to sporulate for several days after plants kept in light had sporulated. Once returned to light, the dark-suppression was immediately reversed, and sporulation commenced within $12 \mathrm{~h}$. Merging of colonies of compatible mating types resulted in near-cessation of sporulation, both in the region of merging and in more distant parts of the colonies. Colonies continued to expand but stopped producing new conidiophores once pairing of compatible mating types had occurred, and extant conidiophores stopped producing new conidia. Therefore, in addition to a quorum-sensing signal to initiate conidiation, there appears to be either signal repression or another signal that causes conidiation to cease once pairing has occurred and the pathogen has initiated the ascigerous stage for overwintering.
\end{abstract} The effect was most pronounced at the lowest inoculum densities, with little decrease of the latent period as the density of inoculation increased

Erysiphe necator (syn. Uncinula necator), the causal agent of grapevine powdery mildew, is the most economically significant fungal pathogen of grape worldwide $(4,13,17,33)$. A characteristic of powdery mildews in general, and E. necator specifically, is the capacity of colonies to produce vast numbers of conidia on a daily basis. Conidia do not require free water for germination and infect throughout a broad range of temperatures encompassing most of the growing season. Increase of powdery mildews does not depend upon punctuated infection events that are moisture limited. The daily production of conidia by E. necator and the steady production of new colonies is a driving force in epidemics. Thus, disruptions in the timing or volume of conidiation could conceivably slow or even stop the progress of disease. Increased understanding of the process of conidiation might allow for direct manipulation of the process, resulting in slowed or reduced production of conidia in the field. Additionally, knowledge of conditions that affect the latent period of the disease or trigger the production of conidia would be of use in the construction of improved forecasting models, thus allowing for more precise timing of fungicides. Previous investigations into the onset of asexual sporulation in E. necator have generally focused upon ratedetermining relationships between temperature, relative humidity,

Corresponding author: D. M. Gadoury; E-mail address: dmg4@ cornell.edu

* The $e$-Xtra logo stands for "electronic extra" and indicates that Figures 1, 4, and 6 appear in color online.

http://dx.doi.org/10.1094/PHYTO-03-11-0085

(C) 2012 The American Phytopathological Society
Additional keywords: Uncinula necator and latent period, as well as quantitative effects of the above factors upon numbers of conidia produced and their survival $(6,10$, 32). However, the factors that signal and control the initiation and maintenance of conidiation itself remain poorly understood. Likewise, little is known of how mating and the transition to production of cleistothecia might affect conidiation. Previous reports indicate that there could be redirection of resources toward the production of cleistothecia once mating has occurred but this has been neither experimentally demonstrated nor quantified. Our objective was to better define the factors involved in the qualitative change that occurs when a mildew colony switches from vegetative growth to sporulation, as well as the changes that might occur in conidiation upon initiation of the ascigerous stage. Preliminary accounts of this work have been published previously $(19,20)$.

\section{MATERIALS AND METHODS}

Microsurgery experiments. Experiments were conducted at the Commonwealth Scientific and Industrial Research Organisation in Adelaide, Australia (CSIRO), and at the New York State Agricultural Experiment Station in Geneva, NY (NYSAES). Mildew-free leaves that were $\approx 50 \%$ expanded were detached from the third node below the shoot apex of potted Vitis vinifera 'Chardonnay' vines (CSIRO) or from seedlings grown from seed harvested from Chardonnay grape (NYSAES). Both types of leaves were surface disinfested for $1 \mathrm{~min}$ in $1 \%$ ( $\mathrm{vol} / \mathrm{vol}$ ) sodium hypochlorite, rinsed three times in distilled water, and placed on $1 \%$ (wt/vol) water agar, adaxial surface uppermost, in petri plates. At 
each location, conidia of $E$. necator were rinsed from fieldcollected leaves using distilled water containing $0.05 \%$ ( $\mathrm{vol} / \mathrm{vol}$ ) Tween 20 (J. T. Baker, Phillipsburg, NJ) to prepare a suspension of $\approx 10^{5}$ conidia/ml. Colonies resulting from these inoculations were reduced to single-spore clones as described by Gadoury and Pearson (16), and the clonal isolates were used in all subsequent experiments.

For each repetition of the experiment, 8 Chardonnay leaves or 10 seedling leaves as described above were inoculated by dispensing three $5-\mu \mathrm{l}$ droplets of suspensions containing a clonal isolate at $10 \mathrm{conidia} / \mathrm{ml}$ onto each side of the midvein of each leaf using a pipette. The resultant six colonies per leaf were incubated under 12 -h day-and-night cycles at $22^{\circ} \mathrm{C}$ under fluorescent plant growth lamps with an illuminance of 2,500 lx (CSIRO) or 2,000 lx (NYSAES). At 3 and 4 days postinoculation (DPI), the edges of each colony on four Chardonnay leaves or five seedling leaves were marked at four points with a fine-point indelible marking pen. Then, $24 \mathrm{~h}$ later ( 4 or $5 \mathrm{DPI}$ ), the center of a colony on each side of the midvein on each of the above leaves, as defined by the area within marked points, was excised. The two uncut colonies on each of the above leaves (one on each side of the midvein) were reserved as controls, as were all colonies on the remaining four Chardonnay leaves or five seedling leaves where no colony centers were excised.

Each day following excisions, the control colonies (both on surgically altered and unaltered leaves) and the remaining colony margins were observed for signs of sporulation. Thus, each excision time was replicated on two colonies on each of four Chardonnay leaves or five seedling leaves and the entire experiment was conducted twice using a single clonal isolate at CSIRO and twice for each of two clonal isolates at NYSAES.

Effect of inoculum density on latent period. Conidia from clonal isolates of E. necator were rinsed from freshly sporulating 7 -day-old colonies using distilled water plus $0.05 \%$ (vol $/ \mathrm{vol}$ ) Tween 20 to prepare a spore suspension containing $10^{5}$ conidia $/ \mathrm{ml}$, as verified by examining conidia within three $10-\mu$ d droplets of the suspension at $\times 400$. The forgoing suspension was immediately diluted to yield a series of eight conidial suspensions containing $4,8,16,32,64,128,256$, or 512 conidia per 5 - $\mu$ l drop.

At CSIRO, Chardonnay leaves were detached, surface sterilized, and placed as above on $1 \%(\mathrm{wt} / \mathrm{vol})$ water agar in petri plates. Each of 10 leaves received one 5- $\mu$ l drop of each concentration of spore suspension, and suspension droplets were allowed to dry before incubating the leaves at $22^{\circ} \mathrm{C}$ (12-h day-and-night cycle). To determine germination potential of the suspension in each repetition of the experiment, a single drop of the densest suspension was placed on each of three glass slides. The slides were incubated at $22^{\circ} \mathrm{C}$ for $8 \mathrm{~h}$ in glass petri plates containing moist filter paper. Percent germination was determined by counting at least 100 conidia on each of the three slides at $\times 400$ magnification. Conidia were classed as "germinated" if they bore a germ tube longer than one-half the length of the conidium. The density of inoculation was determined from the area of the spore deposit resulting from the 5- $\mu$ l droplets (mean of $4.43 \mathrm{~mm}^{2}$ ) adjusted for the percentage of germinating conidia within each prepared conidial suspension. The experiment was conducted twice using a single clonal isolate.

At NYSAES, grapevine seedlings were grown from seed harvested from $V$. vinifera 'Riesling' as previously described (12). Leaves that had expanded to approximately one-half of the size typical of mature leaves were detached, surface sterilized, and placed on water agar as above. Each of 10 leaves received one 5 - $\mu$ drop of each concentration of spore suspension and suspension droplets were allowed to dry before incubating the leaves at $22^{\circ} \mathrm{C}$ (12-h day-and-night cycle) under fluorescent plant growth lamps with an illuminance of 2,500 lx. Germination potential of suspensions was also determined as above. The experiment was conducted twice using two clonal isolates. It was repeated twice more with the same isolates with the following modification: the seedling leaves were left attached and the entire seedling was maintained in isolation in a clear polycarbonate cup covered with a double layer of tissue paper to provide air exchange. Starting 4 DPI at both CSIRO and NYSAES, colonies were observed twice daily at $\times 20$ to $\times 32$ magnification for signs of sporulation. The latent period was recorded as elapsed once $\geq 50 \%$ of the replicated colonies resulting at a particular inoculum concentration had produced conidiophores bearing at least one conidium.

Effect of light on sporulation. The following experiment was conducted at NYSAES. Grapevine seedlings were grown from seed harvested from $V$. vinifera Riesling as previously described (12). Detached leaves from seedlings were surface sterilized and placed on $1 \%(\mathrm{wt} / \mathrm{vol})$ agar plates. Each leaf was inoculated with five 5 - $\mu \mathrm{l}$ drops of a conidial suspension containing $\approx 250$ conidia/ drop. Colonies were allowed to develop under 12-h day-and-night cycles at $22^{\circ} \mathrm{C}$. At $36 \mathrm{~h}$ after inoculation, leaves were divided into three groups: one receiving $24 \mathrm{~h}$ of light per day, one receiving $12 \mathrm{~h}$ of light, and one receiving no light. Starting on day 5, sample leaves were removed and observed at $\times 32$ magnification for signs of sporulation. On day 8 , leaves from all three groups were examined at $\times 32$ magnification and the number of conidiophores per square centimeter at the center of the colony was recorded. Conidial production was also assessed by lightly touching glass microscope slides to colonies and then counting the number of conidia adhering to the slides at $\times 100$ magnification. Finally, on day 8 , colonies borne on leaves which had received no light were exposed to a 12-h day-and-night cycle at $22^{\circ} \mathrm{C}$, and conidiophore and conidial production was assessed as above $24 \mathrm{~h}$ later on day 9. Within each light treatment, 15 to 20 leaves were sampled and the experiment was repeated a total of four times; twice with each of two clonal isolates. The experiment was then repeated twice more in June 2011 with the following modifications: (i) a third clonal isolate for inoculations was obtained from greenhouse-grown Vitis vinifera Chardonnay at NYSAES; (ii) the leaves were incubated for 3 days under a 12-h day-and-night cycle before they were divided into two groups, one receiving $12 \mathrm{~h}$ of light and one receiving no light; and (iii) in addition to assessment of conidial production as before, the diameter of each colony was determined by measuring two axial transects through the colony center at $\times 10$ magnification using the ocular micrometer of a dissecting microscope.

Effect of pairing of compatible mating types on sporulation. The following experiments were conducted at CSIRO in 2003 and at NYSAES in 2004. Isolates of E. necator were reduced to single-spore clones as above, and their compatibility was determined by pairing them on detached Chardonnay leaves in double petri plates as described by Gadoury and Pearson (16). Once the mating types were determined, two clonal isolates (one of each mating type) were selected based upon their ability to grow and sporulate profusely on detached Chardonnay leaves.

Spore suspensions containing each isolate at $10^{5}$ conidia $/ \mathrm{ml}$ were prepared as above, and a single 5 - $\mu$ l droplet of spore suspension was placed on each side of the midvein of a detached Chardonnay leaf in a double petri plate, $\approx 2 \mathrm{~cm}$ apart. Treatments were replicated on single leaves and consisted of (i) droplets on opposite side of the midvein, each containing one of two clonal isolates, or (ii) droplets on opposite sides of the midvein, each droplet containing a 1:1 mixture of both clonal isolates.

The detached leaves were incubated at $23^{\circ} \mathrm{C}$ under a 12 -h dayand-night cycle for 7, 12, or 20 days at CSIRO and 7, 14, or 21 days at NYSAES. Treatments were replicated on six leaves per sampling interval. Sporulation was destructively sampled on the above indicated days by shaking each leaf in $10 \mathrm{ml}$ of distilled water plus $0.05 \%$ ( $\mathrm{vol} / \mathrm{vol}$ ) Tween 20 , and transferring a $20-\mu \mathrm{l}$ droplet of the resultant suspension to a glass microscope slide. The deposit was allowed to dry and mounted in lactoglycerol, and the spores on the slide were enumerated at $\times 200$ magnification. 
The experiment was performed twice at both CSIRO and NYSAES.

To compare resporulation on conidiophores after removal of conidia in each of the above treatments, an additional three leaves were inoculated as above with either single clonal isolates or paired clonal isolates that were sexually compatible, and were incubated for 10 days. Conidia were then manually dislodged from any sporulating areas of the mildew colonies by removing the leaf from the agar surface with sterile forceps, inverting the leaf and forcefully tapping the lower surface with a glass rod, and then replacing the leaf in its former position in the petri plate. Removal of existing conidia was confirmed by examination of the colonies at $\times 32$, and the leaves were returned to incubation. Colonies were examined for resporulation after $24 \mathrm{~h}$ and again after $48 \mathrm{~h}$ at $\times 32$. The number of conidia borne on $\leq 30$ conidiophores per plate was recorded for each time interval. The experiment was repeated with the following modification: the plates were examined beginning 9 DPI.

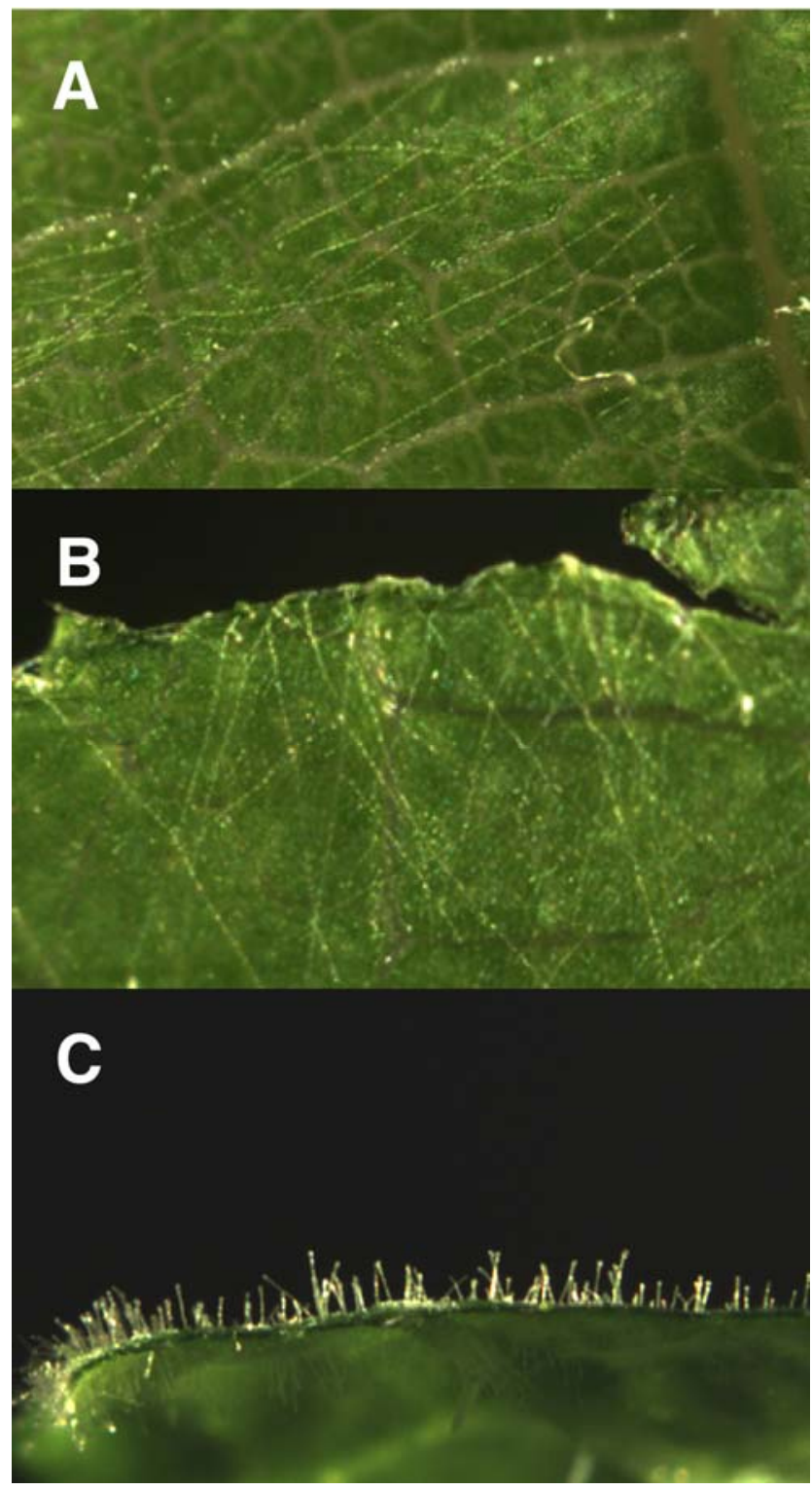

Fig. 1. Effect of microsurgical removal of portions of the colony on conidiation of Erysiphe necator. A, Presporulation growth at the margin of a 4-day-old mildew colony; B, continued radial growth of mildew colony without sporulation on day 7 following excision of colony center on day 4; and $\mathbf{C}$, sporulation at margin of mildew colonies on day 7 following excision of center of mildew colony on day 5 .

\section{RESULTS}

Timing of the sporulation signal. Microsurgery experiments carried out in different locations (CSIRO and NYSAES) using a variety of host tissue and different $E$. necator isolates consistently demonstrated that removal of the colony center on day 4 substantially delayed sporulation but removal of the colony center on day 5 did not affect the length of the latent period. With the exception of 2 of the 24 leaves that were surgically altered that died before the experiment was completed, excision of the colony center at 4 DPI delayed sporulation in the remaining hyphae until 9 to 10 DPI in all replicates and repeats of the experiment (Fig. 1). A similar uniformity of response was observed in the 23 of 24 surviving control leaves and 22 of 24 surviving leaves whose colony centers were excised on day 5 after inoculation: all sporulated on day 7 following inoculation (Fig. 1). At the time of sporulation on day 7 , the sporulating hyphae remaining at the margin of colonies whose centers were excised on day 5 were a maximum of 2 days old.

Effect of inoculum density on latent period. The length of the latent period of the clonal isolate collected in Adelaide, Australia on detached Chardonnay leaves $22^{\circ} \mathrm{C}$ varied from a maximum of $\approx 8$ days to a minimum of 5 days, depending upon the density of inoculation (Fig. 2A). Because the variances of latent period were homogeneous for both repetitions of the experiment $(P<0.001)$, the results were pooled and analyzed by regression.

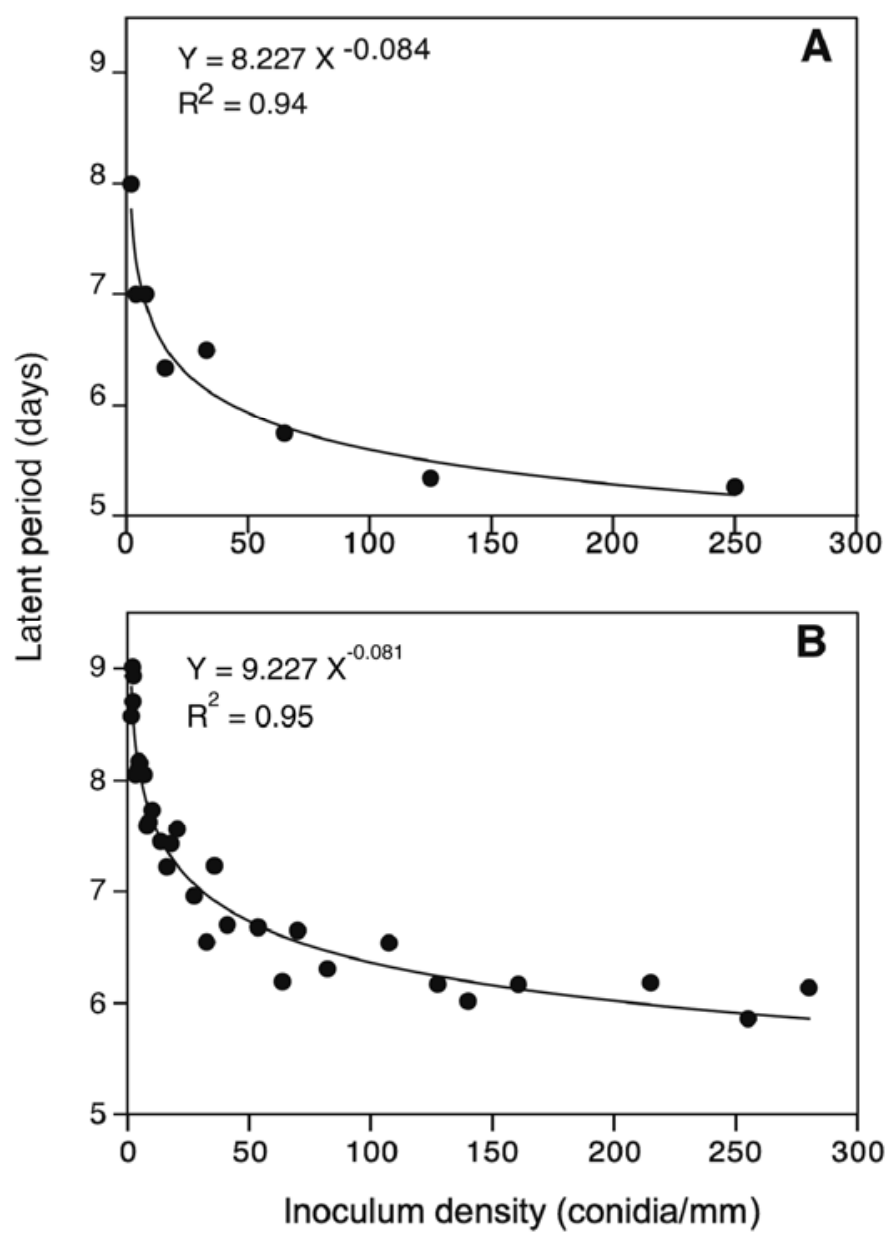

Fig. 2. Effect of increasing inoculation density on duration of latent period of Erysiphe necator. A, Leaves were detached from potted vines of Vitis vinifera 'Chardonnay', placed on water agar in petri plates, and inoculated with a clonal isolate from Adelaide, Australia; or B, V. vinifera seedling leaves were detached and placed on water agar in petri plates as above, or were left attached to seedlings, inoculated with one of three clonal isolates collected in Geneva, NY, incubated at $22^{\circ} \mathrm{C}$, and observed daily for signs of conidiation. 
The latent period decreased exponentially as the number of germinable conidia increased above 1 conidium $/ \mathrm{mm}^{2}$ (Fig. 2A) until inoculation density reached $\approx 10$ to 20 germinable conidia/ $\mathrm{mm}^{2}$. Regression of the observed latent period against the number of germinable conidia per square millimeter yielded the following model: $Y=8.227, X^{-0.084}, R^{2}=0.94$, where $Y=$ latent period (days) and $X=$ density of germinable conidia per square millimeter. Increasing the conidial density from 25 to 250 conidia/ $\mathrm{mm}^{2}$ produced only a slight decline in the duration of the latent period (i.e., from $\approx 6$ days to $\approx 5$ days) (Fig. 2 A).

Minimum latent period of the clonal isolates from NYSAES on $V$. vinifera seedling leaves was $\approx 6$ days (Fig. $2 \mathrm{~B}$ ), or $\approx 1$ day longer than the minimum latent period observed on Chardonnay leaves at CSIRO (Fig. 2A). Variances of latent periods of the isolates collected at NYSAES were homogeneous both between clonal isolates and between repetitions of the experiment, and between detached leaves and leaves left attached to the seedlings $(P<0.001)$; therefore, the results were pooled and analyzed by regression. Regression of the observed latent period against the number of germinable conidia per square millimeter yielded a result similar to that obtained for the isolate at CSIRO, where the most pronounced decrease in latent period was observed as density of inoculum deposition was increased from 1 to $\approx 25$ conidia/ $\mathrm{mm}^{2}$ (Fig. 2B): $Y=9.227, X^{-0.081}, R^{2}=0.95$, where $Y=$ latent period (days) and $X=$ density of germinable conidia per square millimeter.

Linear regression of latent period against conidial density $>25$ conidia $/ \mathrm{mm}^{2}$ yielded a slope coefficient not significantly different from $0(P=0.05)$ for the pooled isolates collected at NYSAES (Fig. 2B).

Effect of light on sporulation. Light was found to be necessary for initiation of sporulation (Fig. 3). No sporulation occurred in the absence of light, whereas $\approx 10 \%$ of colonies exposed to 12-h day-and-night cycles or continuous light sporulated on day 5 and $100 \%$ of the colonies had sporulated by day 7 . Colonies allowed to grow under a normal day-and-night cycle for $36 \mathrm{~h}$ but thereafter kept in darkness did not sporulate on days 5 to 7 . However, when colonies that had been incubated in darkness until day 7 were thereafter exposed to a 12-h day-and-night cycle,

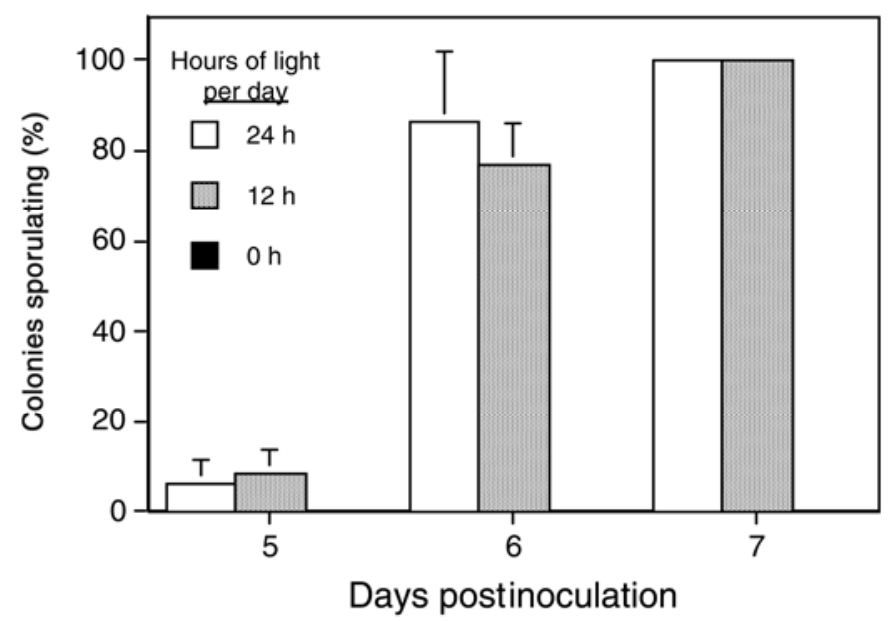

Fig. 3. Effect of light and dark treatments on sporulation of Erysiphe necator. Leaves detached from Vitis vinifera seedlings were inoculated, colonies were allowed to develop under a 12 -h day-and-night cycle at $22^{\circ} \mathrm{C}$ for $36 \mathrm{~h}$, and then the leaves were divided among three treatments: $24 \mathrm{~h}$ of light per day, $12 \mathrm{~h}$ of light per day, and $0 \mathrm{~h}$ of light per day (constant darkness). At 5, 6, and 7 days after inoculation, the leaves were examined at $\times 32$ magnification for signs of sporulation. No bars are visible for the 0 -h treatments because only mycelial growth occurred in constant darkness. Error bars indicate one standard error of the mean. No error bars are show for the 7-day assessment because $100 \%$ of the colonies had sporulated in all replicates (standard error $=0$ ). conidiophores developed at the margin of the colony on day 8, and mature conidia were produced on day 9. Thus, colonies incubated in darkness were competent for sporulation but required light to initiate the process.

At 6 DPI, leaves grown continually under 12-h day-and-night cycles bore colonies that did not differ significantly $(P=0.05)$ in diameter from colonies that developed on leaves kept in complete darkness after 3 days of growth under a 12-h day-and-night cycle (i.e., after three additional days of growth in complete darkness).

Effect of pairing of compatible mating types on sporulation. Spore suspensions placed on opposite sides of the leaf midvein gave rise to colonies that were 3 to $4 \mathrm{~mm}$ in diameter by 4 DPI and remained separated from adjacent colonies. Clonal isolates collected in Australia and New York sporulated within 7 DPI when maintained as distinct clones (Figs. 4 and 5) and continued to produce progressively greater numbers of conidia when sporulation was assessed 12 to 14 and 20 to 21 DPI (Fig. 5). However, when sexually compatible clonal isolates were paired and the resultant colonies merged and mating occurred, sporulation was greatly reduced (Fig. 5). Sporulation remained at trace levels until the experiment was terminated, at which time sporulation among the mated isolates was $<5 \%$ of the level observed among the same isolates grown separately (Fig. 5).

When conidia were manually dislodged from extant conidiophores within colonies of a clonal isolates grown singly (Fig. 4A), resporulation was observed on $45.3 \%$ ( $\mathrm{SE}=6.44 \%$ ) of conidiophores at $24 \mathrm{~h}$ and $68.6 \%$ ( $\mathrm{SE}=8.54 \%$ ) of the conidiophores at $48 \mathrm{~h}$, and the modal number of conidia borne was 1 at $24 \mathrm{~h}$ after dislodgement, and 2 at $48 \mathrm{~h}$ after dislodgement. In contrast, among colonies comprised of a mixture of the clonal isolates in which mating was underway, resporulation was observed on only $2.5 \%$ (standard error $[\mathrm{SE}]=1.97 \%$ ) of the conidiophores at $24 \mathrm{~h}$ and $3.5 \%(\mathrm{SE}=3.45 \%$ ) of the conidiophores $48 \mathrm{~h}$ after dislodgement, and the modal number of conidia borne was 0 at both 24 and 48 h (Fig. 4D).

\section{DISCUSSION}

Our study has revealed several factors that affect conidiation of $E$. necator, including prior vegetative growth, inoculum density, light, and mating. Previous studies of conidiation in E. necator have shown that colonies composed of a single mating type undergo a period of vegetative growth for $\approx 5$ to 9 days prior to production of conidiophores and conidia (32). At $\approx 6$ to 9 DPI, conidiophores appear singly and in small groups throughout $E$. necator colonies, including areas near the margin of the colony where the hyphae are less than $48 \mathrm{~h}$ old. This is consistent with production of a signal that coordinates synchronous development of conidiophores throughout the body of the colony. The requirement of a period of asexual growth before reaching competence for sporulation has also been demonstrated in other model fungi, including Aspergillus nidulans and Neurospora crassa $(1,2)$.

The results of the microsurgery experiments described here provide further circumstantial evidence that initiation of asexual sporulation is triggered through a coordinating signal. Five-dayold colonies wherein all hyphae except those at the colony margin were excised began to sporulate 7 DPI, in time with unaltered controls. However, sporulation was greatly delayed in 4-day-old colonies subjected to the same treatment. These results indicate that the timing of sporulation may be reset by removing the colony center on day 4 . By day 5 , the sporulation process appears to have been initiated and was not reversed by excising the colony centers. Although the nature of a putative triggering signal in $E$. necator remains unknown, it appears to act throughout the colony, including 1-day-old hyphae at the colony margin.

Increasing inoculum density was shown to decrease the latent period, suggesting that colony density is perhaps an operative factor driving promulgation of the sporulation signal, and that the 
critical density might be achieved either through time or by an increased initial density within nascent colonies. Colonies of $E$. necator might require a critical density before a signal is produced or reaches an effective intensity to initiate sporulation. A similar process has been suggested for A. nidulans, wherein the flu G gene produces a small diffusible factor consistently associated with sporulation (27). Lee and Adams (27) hypothesized that sporulation in A. nidulans was triggered when the concentration of volatile FluG exceeded a critical threshold (27). Inoculum density has also been shown to decrease the latent period, albeit to a lesser degree than we observed in E. necator, in inoculations of potato leaves using zoospore suspensions of Phytophthora infestans (26). Additionally, measurement of disease severity determined that the number of pathogen colonies per unit of host tissue was inversely proportional to the duration of the latent period in E. graminis f. sp. tritici (37).

Although quorum-sensing phenomena have not been well characterized in fungi, other morphogenesis events in fungi have been similarly linked to density responses. Quorum sensing was first discovered among the eukaryotes in Candida albicans, where farnesol acts as the quorum-sensing molecule that suppresses both the mycelial state of the organism and the formation of biofilms above a threshold population $(24,35)$. Quorum-sensing links have also been observed between population density and colony morphology in the elm pathogen Ceratocystis ulmi (23), between spore density and germination in Uromyces phaseoli (28), and among several aspects of development in dimorphic fungi (31).

Should signaling prove to play an active role in asexual sporulation in E. necator, disrupting the pathways involved might provide a novel means of control. Disruption of quorum signaling has reduced the pathogenicity of several gram-negative bacterial pathogens, and transgenic crops expressing disrupters of quorum signaling have shown increased resistance in lab trials (9). Similar strategies could conceivably be employed in fungi such as $E$. necator if signaling should prove to be involved at critical developmental stages.

Our findings also have implications for the design of field and laboratory experiments related to forecasting development of powdery mildew epidemics. Both latency (Fig. 2) and the appearance of macroscopically visible colonies (Fig. 6) is strongly affected by inoculum dose. Previous experimental inoculations have generally involved the transfer or application of large numbers of conidia to host tissues to ensure successful infection and establishment of the pathogen. This is in contrast to infection resulting from airborne conidia in a natural setting, where colonies might be dependent upon the success or failure of a single conidium to become established. Thus, latent periods and estimated rates of epidemic development in extant models may require adjustment if based upon experimental inoculations using unrealistically high numbers of conidia. Our supposition that natural generation of

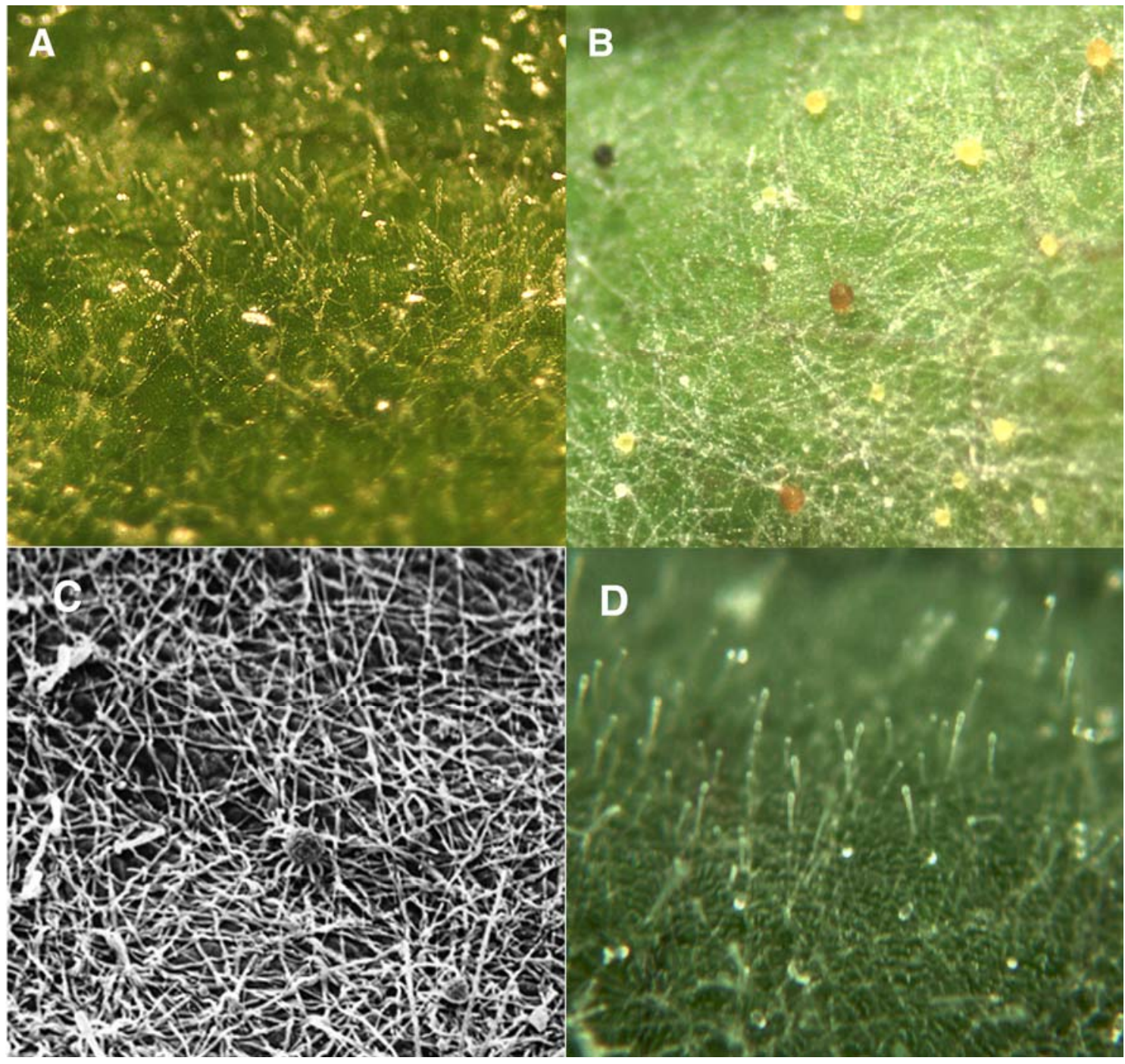

Fig. 4. A, Abundant sporulation of a mildew colony of a single mating type; $\mathbf{B}$, absence of sporulation within a mildew colony composed of two compatible mating types accompanied by production of cleistothecia; $\mathbf{C}$, scanning electron micrograph of colony comprised of compatible mating types showing immature ascocarp and absence of conidiophores; and $\mathbf{D}$, conidiophores bearing only conidiogenous cells at margin of mating colony $48 \mathrm{~h}$ after removal of existing conidia. 

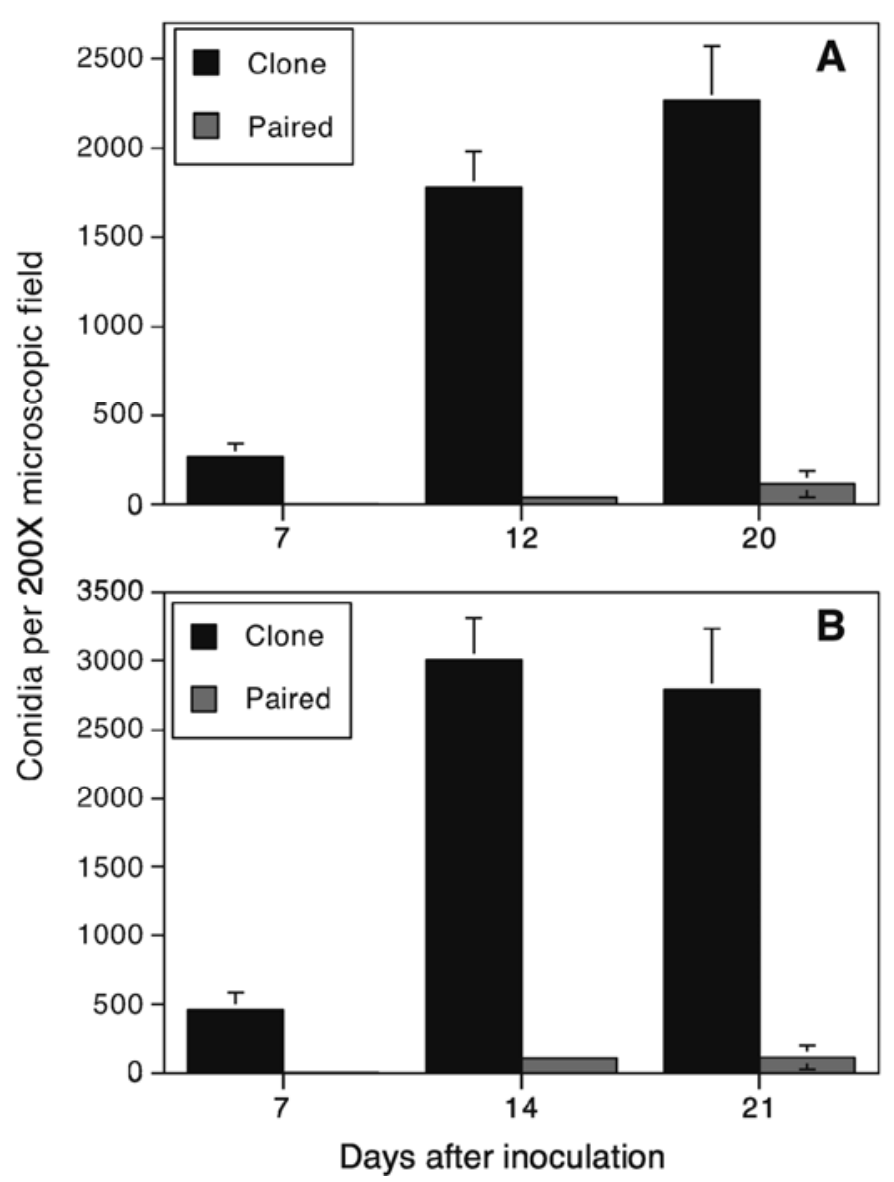

Fig. 5. Effect of mating of sexually compatible isolates of Erysiphe necator on asexual sporulation. Single-spore (clonal) isolates collected at $\mathbf{A}$, Adelaide, Australia and B, Geneva, NY were dispensed upon leaves of Vitis vinifera 'Chardonnay' leaves as either single clones (clone, above) or as mixtures of two compatible isolates (paired, above). Sporulation was assessed at 7, 12 to 14 , and 20 to 21 days after inoculation. Bars represent means of two repeats of the experiment. Error bars denote one standard error of the mean. Bars not visible indicate near-zero values.

mildew colonies in vineyards most typically occurs from single propagules is supported by airborne ascosporic and conidial densities reported in vineyards $(5,15)$ and observed disease development on potted vines deployed as trap plants (W. Mahaffee, personal communication).

E. necator can overwinter as cleistothecia or as mycelium within dormant infected buds. Cleistothecia contain $\approx 6$ asci, each of which contain four to six ascospores at maturity (14). Reported concentrations of airborne ascospores in vineyard studies $(15,22$, 36) are insufficient to account for successful infection of individual leaves by multiple spores; thus, most ascosporic colonies are likely to arise from single ascospores. Therefore, inoculum density would not be expected to affect the latent period of colonies arising from ascosporic infections, assuming a similar density-dependent response. However, mycelium overwintering in dormant buds give rise to "flag shoots" which may support densely sporulating colonies over much of their surface area. Such an intense point source of conidial inoculum could result in dispersal and deposition of multiple conidia at the same point on a leaf surface close to the source and, thereby, give rise to colonies with commensurately shortened latent periods. It is important to note that substantial reductions in latent period were observed with relatively modest increases above one spore (Fig. 3). In the foregoing scenario, flag shoots, in addition to producing distinct foci of infection, might simulate the effects of increased virulence, because latency could conceivably be reduced by the intensity of the point source of inoculum. Such a process, over time, might determine whether progeny of ascosporic colonies or flag shoots would predominate in the vineyard. The highly conspicuous nature of flag shoots, coupled with the highly inconspicuous appearance of ascosporic colonies (32), could create substantial challenges in sampling the relative contributions of each source early in an epidemic. All of the foregoing is admittedly quite speculative but, perhaps, merits further study at the population level. It may be directly relevant to managing epidemics from fundamentally different sources of inoculum and the enigmatic population dynamics of flag shoot and ascosporic isolates reported in some studies $(11,13)$.

Density-dependent development of E. necator might also explain another phenomenon observed in diffuse infection of grape berries (18). Berries of $V$. vinifera exhibit high susceptibility to infection for a period of $\approx 2$ weeks post-bloom. Ontogenic resistance develops in the berry epidermis within 7 to 10 days thereafter, and further new infections of powdery mildew are greatly reduced $(12,18)$. Diffuse and nonsporulating infections are commonly found on berries infected during the transitional stages between moderate susceptibility and near-immunity (18). This colony phenotype would be consistent with the failure to reach a critical colony density required to promulgate a signal for sporulation, thus keeping the colonies in their observed, diffuse, and purely vegetative state. Likewise, the extended latent periods recently documented by Moyer et al. (30) for E. necator colonies exposed to acute cold events may be related to the mortality of hyphae within developing colonies, consequent reductions in colony density, and a delay in reaching a critical density required for sporulation.

In addition to establishing linkage between colony density and initiation of sporulation, our studies indicated that light functioned as a trigger for asexual sporulation in E. necator once colonies reach a critical density. The role of light as a modifier of asexual development is a common theme in filamentous fungi. In A. nidulans, asexual sporulation is repressed in the dark, reduced in blue or red light, and stimulated by white light (34). Photoinduction of conidiation by blue light has also been demonstrated in Paecilomyces fumosoroseus, Alternaria tomato, and Trichoderma atroviride $(7,25,39)$. More recently, Suthparan et al. (41) reported that conidiation in the rose powdery mildew pathogen Podosphaera pannosa was stimulated by blue light (420 to $520 \mathrm{~nm}$ ) but repressed by red light (620 to $720 \mathrm{~nm})$. Several lightsensing systems have been identified in fungi, including a phytochrome in Aspergillus nidulans, FphA, that represses sexual development in the presence of red light (3), and it is possible that similar complexes may be active in E. necator, other powdery mildews, and perhaps many and diverse fungi. The rapidity with which sporulation can be induced in E. necator upon exposure of dark-suppressed but sporulation-competent colonies to light may provide a model system for the study of metabolic pathways operational in the process.

The obligate nature of E. necator makes separation of the direct effects of light or darkness upon the pathogen from the indirect effects via the plant problematic. It is possible that suppression of sporulation in darkness might result from indirect effects exerted upon the host, such as cessation of photosynthesis or nutrient depletion. However, colonies removed from darkness into light produced conidiophores within a few hours. Also, previous observations on growth and sporulation of E. necator indicated that sporulation was delayed or reduced but not prevented on nutrientdeficient plants (14), and photosynthesis takes place in tissues other than the epidermal cells parasitized by E. necator. If the lack of sporulation in dark-grown colonies resulted from nutrient depletion or lack of photosynthesis in a stressed host, it seems unlikely that the host would recover quickly enough to provide the limiting factor in just a few hours. Furthermore, colony diameter was not affected by growth of colonies in complete darkness for 3 days. Therefore, it seems most likely that light operates as a 


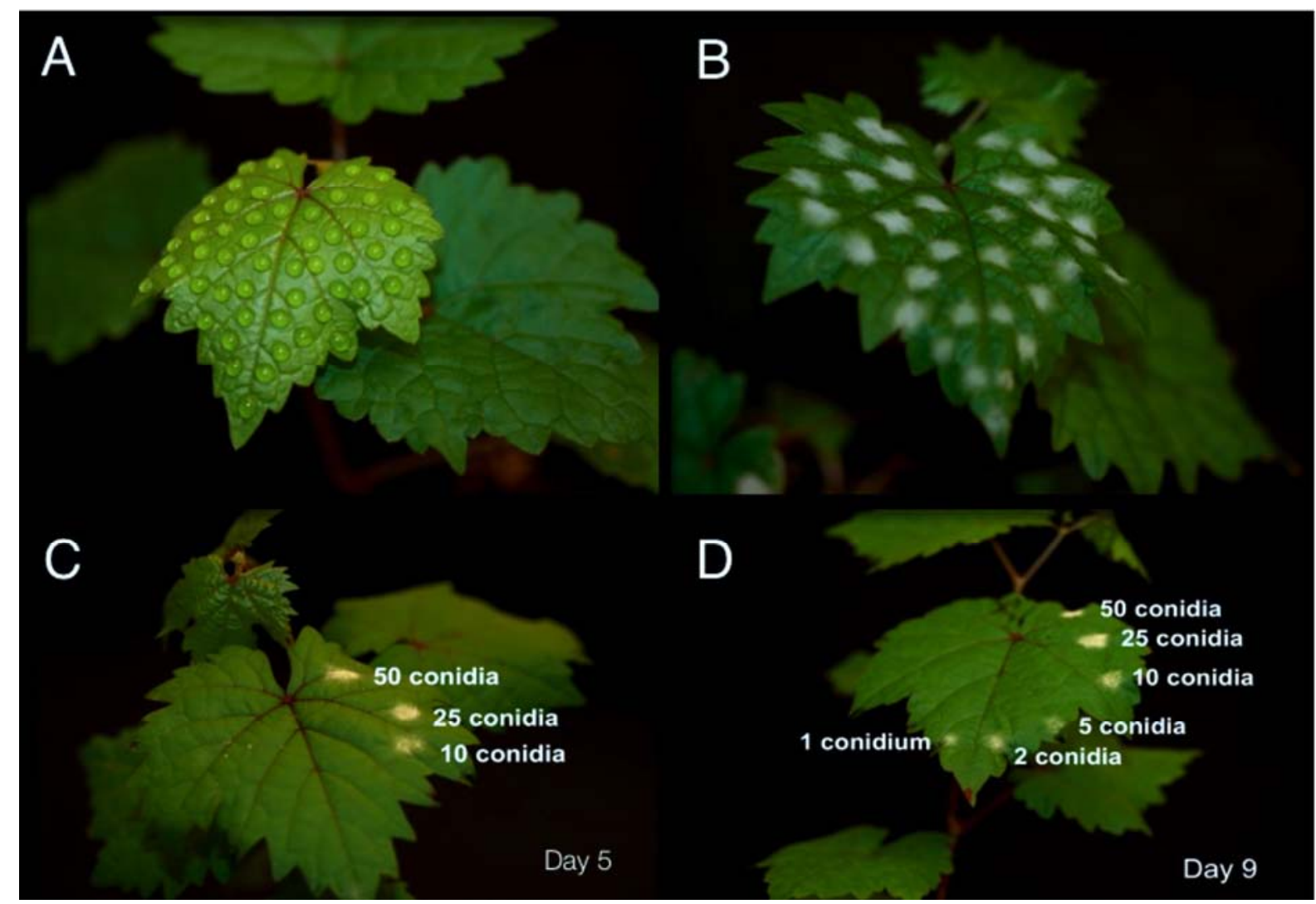

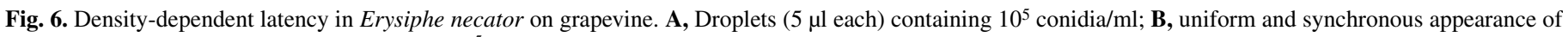

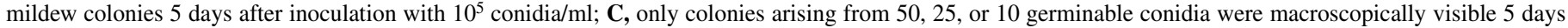

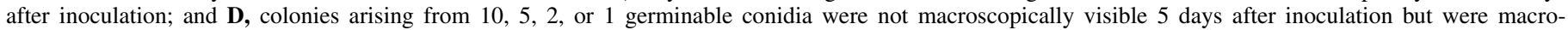
scopically visible at 9 days after inoculation.

signal to initiate sporulation once the colonies reach a critical age or density.

The above experiments provide substantial preliminary evidence for a signal coordinating induction of sporulation in $E$. necator and that this signal may be affected by both colony density and the presence of light. The role of colony density, in particular, in early developmental events has significant implications for both forecasting models and potentially novel avenues of control. Furthermore, the discovery that conidiation in sporulation-competent colonies can be manipulated by light and dark treatments suggests a useful experimental tool for further genetic studies, wherein gene expression and regulation can be examined in a temporally precise fashion in sporulation-competent colonies during the minutes before and after light exposure.

The sequence of morphogenesis involved in development of cleistothecia of E. necator is complex but ordered (14). The pairing of compatible mating types effectively prevented the initiation of sporulation throughout much of the colony. It seems unlikely to us that the failure to sporulate resulted purely from a source-sink relationships, wherein resources for sporulation were reallocated based upon a demand to increase biomass. Rather, the failure to produce conidiophores or conidia was determined soon after hyphal contact between compatible mating types, before there would be a substantial increase in biomass due to formation of ascocarp initials (14). Indeed, compared with colonies in which sporulation had occurred, there appeared to be a net decline in the rate of biomass production due to the cessation of conidial production prior to significant accumulation of cleistothecial biomass. Furthermore, conidial production ceased or declined sharply on extant conidiophores throughout the mildew colony where mating had occurred. The above process is consistent with either the promulgation of a biochemical signal to shut down sporulation or the cessation of a signal that maintains the process.
The magnitude of the effect of mating upon asexual sporulation is not trivial. It is substantial and can be observed at the wholeplant, vineyard, or ecosystem level. The observation that disease progress in this pathosystem becomes asymptotic late in the season (40) is coincidentally related to the time that cleistothecia are being initiated $(8,14,21,22,29,36,38)$, and might reflect a cessation of sporulation due to ascocarp initiation. A more comprehensive understanding of the fundamental nature of the signal process either in nascent colonies or within colonies that are shifting from production of conidia to production of the ascigerous state may allow the process to be manipulated as a means of managing this or other powdery mildews. We are continuing our research in this area, and have recently reported on differential gene expression during conidiation in E. necator (42).

\section{ACKNOWLEDGMENTS}

This work was supported by the United States Department of Agriculture Viticulture Consortium-East, The Pennsylvania Wine Marketing Board, and the New York Wine and Grape Foundation. Part of the research described herein represents a portion of a dissertation submitted by L. M. Wakefield to the Graduate School of Cornell University in partial fulfillment of the requirements for the Ph.D. in Plant Pathology. Studies on the growth of mildew colonies during darkness were conducted by M. K. Schappert as part of a Research Experience for Undergraduates in Plant Pathology at Cornell during June and July 2011.

\section{LITERATURE CITED}

1. Adams, T. H., Wiser, Y. U, and Yu, J-H. 1998. Asexual sporulation in Aspergillus nidulans. Microbiol. Mol. Biol. Rev. 62:35-54.

2. Bailey-Shrode, L., and Ebbole, D. J. 2004. The fluffy gene of Neurospora crassa is necessary and sufficient to induce conidiophore development. Genetics 166:1741-1749. 
3. Blumenstein, A., Vienken, K., Tasler, R., Purschwitz, J., Vith, D., Frankenberg-Dinkel, N., and Fischer, R. 2005. The Aspergillus nidulans phytochrome FphA represses sexual development in red light. Curr. Biol. 15:1833-1838.

4. Bulit, J., and Lafon, R. 1978. Powdery mildew of the vine. Pages 525-548 in: The Powdery Mildews. D. M. Spencer, ed. Academic Press, London.

5. Carisse, O., Bacon, R., and Lefebvre, A. 2009. Grape powdery mildew (Erysiphe necator) risk assessment based on airborne conidium concentration. Crop Prot. 28:1036-1044.

6. Carroll, J. E., and Wilcox, W. F. 2003. Effects of humidity on the development of grapevine powdery mildew. Phytopathology 93:1137-1144.

7. Casas-Flores, S., Rios-Momberg, M., Rosales-Saavedra, T., MartínezHernández, P., Olmdo-Monfil, V., and Herrera-Estrella, A. 2006. Cross talk between a fungal blue light perception system and the cyclic AMP signaling pathway. Eukaryot. Cell 5:499-506.

8. Cortesi, P., Bisiach, M., Ricciolini, M., and Gadoury, D. M. 1997. Cleistothecia of Uncinula necator: An additional source of inoculum in Italian vineyards. Plant Dis. 81:922-926.

9. Cui, X., and Harling, R. 2005. N-acyl-homoserine lactone-mediated quorum sensing blockage, a novel strategy for attenuating pathogenicity of Gramnegative bacterial plant pathogens. Eur. J. Plant Pathol. 111:327-339.

10. Delp, C. J. 1954. Effect of temperature and humidity on the grape powdery mildew fungus. Phytopathology 44:615-626.

11. Délye, C., Laigret, F., and Corio-Costet, M. F. 1997. RAPD analysis provides insight into the biology and epidemiology of Uncinula necator. Phytopathology 87:670-677.

12. Ficke, A., Gadoury, D. M., Seem, R. C., and Dry, I. B. 2003. Effects of ontogenic resistance upon establishment and growth of Uncinula necator on grape berries. Phytopathology 93:556-563.

13. Gadoury, D. M., Cadle-Davidson, L., Wilcox, W. F., Dry, I. B., Seem, R. C., and Milgroom, M. G. Grapevine powdery mildew (Erysiphe necator): A fascinating system for the study of the biology, ecology, and epidemiology of an obligate biotroph. Mol. Plant Pathol. DOI: 10.1111/ j.1364-3703.2011.00728.x.

14. Gadoury, D. M., and Pearson, R. C. 1988. Initiation, development, dispersal and survival of cleistothecia of Uncinula necator in New York vineyards. Phytopathology 78:1413-1421.

15. Gadoury, D. M., and Pearson, R. C. 1990. Ascocarp dehiscence and ascospore discharge in Uncinula necator. Phytopathology 80:393-401.

16. Gadoury, D. M, and Pearson, R. C. 1991. Heterothallism and pathogenic specialization in Uncinula necator. Phytopathology 81:1287-1293.

17. Gadoury, D. M., Seem, R. C., Pearson, R. C., and Wilcox, W. F. 2001. Effects of powdery mildew on vine growth, yield, and quality of Concord grapes. Plant Dis. 85:137-140.

18. Gadoury, D. M., Seem, R. C., Wilcox, W. F., Henick-Kling, T., Conterno, L., Day, A., and Ficke, A. 2007. Effects of diffuse colonization of grape berries by Uncinula necator on bunch rots, berry microflora, and juice and wine quality. Phytopathology 97:1356-1365.

19. Gadoury, D. M., Wakefield, L. M., Seem, R. C., Cadle-Davidson, L., and Dry, I. B. 2004. Preliminary studies of signaling and sporulation in Uncinula necator. (Abstr.) Phytopathology 94:S33.

20. Gadoury, D. M., Wakefield, L. M., Seem, R. C., Cadle-Davidson, L., and Dry, I. B. 2010. Effect of prior vegetative growth, inoculum density and light on conidiation in Erysiphe necator. Pages 51-53 in: Proc. 6th Int. Workshop Grapevine Downy and Powdery Mildew. A. Calonnec, F. Delmotte, R. Emmett, D. M. Gadoury, C. Gessler, D. Gubler, H.-H. Kassemeyer, P. A. Magarey, M. Raynal, and R. C. Seem, eds. INRA Bordeaux-Aquitaine, Bordeaux, France.

21. Gee, L. M., Stummer, B. E., Gadoury, D. M., Biggins, L. T., and Scott, E. S. 2000. Maturation of cleistothecia of Uncinula necator (powdery mildew) and release of ascospores in southern Australia. Aust. J. Grape Wine Res. 6:13-20.

22. Grove, G. G. 2004. Perennation of Uncinula necator in vineyards of Eastern Washington. Plant Dis. 88:242-247.

23. Hornby, J. M., Jacobitz, S. M., McNeel, D. J., Jensen, E. C., Treves, D. S., and Nickerson, K. W. 2004. The inoculum size effect in dimorphic fungi: extra-cellular control of yeast mycelial dimorphism in Ceratocystis ulmi. Appl. Environ. Microbiol. 70:1356-1359.

24. Hornby, J. M., Jensen, E. C., Lisec, A. D., Tasto, J. J., Jahnke, B., Shoemaker, R., Dussault, P., and Nickerson, K. W. 2001. Quorum sensing in the dimorphic fungus Candida albicans is mediated by farnesol. Appl. Environ. Microbiol. 67:2982-2992.

25. Kumagai, T. 1989. Temperature and mycochrome system in near- UV light inducible and blue light reversible photoinduction of conidiation in Alternaria tomato. Photochem. Photobiol. 50:793-798.

26. Lapwood, D. H., and McKee, R. K. 1966. Dose-response relationships for infection of potato leaves by zoospores of Phytophthora infestans. Trans. Br. Mycol. Soc. 49:679-686.

27. Lee, B. N., and Adams, T. H. 1996. fluG and flbA function interdependently to initiate conidiophore development in Aspergillus nidulans through the brlA beta activation. EMBO J. 15:299-309.

28. Macko, V., Staples, R. C., Gershon, H., and Renwick, J. A. 1970. Selfinhibitor of bean rust uredospores: methyl 3,4-dimethoxycinnamate. Science 170:539-540.

29. Magarey, P. A., Gadoury, D. M., Emmett, R. W., Biggins, L. T., Clarke, K., Wachtel, M. F., Wicks, T. J., and Seem, R. C. 1997. Cleistothecia of Uncinula necator in Australia. Vitic. Enol. Sci. 52:210-218.

30. Moyer, M. M., Gadoury, D. M., Cadle-Davidson, L., Dry, I. B., Magarey, P. A., Wilcox, W. F., and Seem, R. C. 2010. Effects of acute lowtemperature events on development of Erysiphe necator and susceptibility of Vitis vinifera. Phytopathology 100:1240-1249.

31. Nickerson, K. W., Atkin, A. L., and Hornby, J. M. 2006. Quorum sensing in dimorphic fungi: Farnesol and beyond. Appl. Environ. Microbiol. 72:3805-3813.

32. Pearson, R. C., and Gadoury, D. M. 1992. Grapevine powdery mildew. Pages 129-146 in: Plant Diseases of International Importance, Vol. III, Diseases of Fruit Crops. J. Kumar, H. S. Chaube, U. S. Singh, and A. N. Mukhopadhyay, eds. Prentice Hall, Englewood Cliffs, NJ.

33. Pearson, R. C., and Goheen, A. C. 1988. Compendium of Grape Diseases. American Phytopathological Society Press, St. Paul, MN

34. Purschwitz, J., Muller, S., Kastner, C., Schoser, M., Haas, H, Espeso, E. Atoui, A., Calvo, A., and Fischer, R. 2008. Functional and physical interaction of blue- and red-light sensors in Aspergillus nidulans. Curr. Biol. 18:255-259.

35. Ramage, G., Saville, S. P., Wickes, B. L., and Lopez-Ribot, J. L. 2002. Inhibition of Candida albicans biofilm formations by farnesol, a quorum sensing molecule. Appl. Environ. Biol. 68:5459-5463.

36. Rossi, V. Caffi, T., and Leger, S.E. 2010. Dynamics of ascospore maturation and discharge in Erysiphe necator, the causal agent of grape powdery mildew. Phytopathology 100:1321-1329.

37. Rouse, D. I., MacKenzie, D. R., and Nelson, R. R. 1984. Density dependent sporulation of Erysiphe graminis f. sp. tritici. Phytopathology 74:1176-1180.

38. Rugner, A., Rumbolz, J., Huber, B., Bleyer, G., Gisi, G., Kassemeyer, H., and Guggenheim, R. 2002. Formation of overwintering structures of Uncinula necator and colonization of grapevine under field conditions. Eur. J. Plant Pathol. 21:322-330.

39. Sánchez-Murillo, R. I., Torre-Martinez, M., Aguirre-Linares, J., and Herrra-Estrella, A. 2004. Light-regulated asexual reproduction in Paecilomyces fumoroseus. J. Microbiol. 150:311-319.

40. Seem, R. C. 1984. Disease incidence and severity relationships. Annu. Rev. Phytopathol. 22:133-150.

41. Suthaparan, A., Torre, S., Stensvand, A., Herrero, M. L., Pettersen, R. I., Gadoury, D. M., and Giselrød, H. R. 2010. Specific light-emitting diodes can suppress sporulation of Podosphaera pannosa on greenhouse roses. Plant Dis. 94:1105-1110.

42. Wakefield, L., Gadoury, D. M., Seem, R. C., Milgroom, M. G., Sun, Q. and Cadle-Davidson, L. 2011. Differential gene expression during conidiation in the grape powdery mildew pathogen, Erysiphe necator. Phytopathology 101:839-846. 